\title{
Influence of (hydrous) ethanol blends on (particle) emissions of small 2-\& 4-stroke scooters Part 1
}

\begin{abstract}
The objectives of the present work are to investigate the regulated and unregulated (particle) emissions of a classical and modern 2-stroke and a typical 4-stroke scooter with different ethanol blend fuels. There is also comparison of two different ethanol fuels: pure ethanol (E) and hydrous ethanol (EH) which contains 3.9\% water and is denatured with $1.5 \%$ gasoline. Special attention is paid in this research to the hydrous ethanol, since the production costs of hydrous ethanol are much less than those for (dry) ethanol.

The vehicles are with carburettor and without catalyst, which represents the most frequent technology in Eastern Asia and offers the information of engine-out emissions. Exhaust emissions measurements have been performed with fuels containing ethanol (E), or hydrous ethanol (EH) in the portion of 5, 10, 15 and 20\% by volume. During the test systematical analysis of particle mass (PM) and nanoparticles counts (NP) were carried out.

The present investigations did not concern the durability of parts exposed to the chemical influences of ethanol. Also the cold start, particularly in extreme conditions and the lube oil dilution were not addressed.
\end{abstract}

Keywords: ethanol, particle emission,2-stroke engines, scooters

\section{Wplyw mieszanek etanolowych na emisję cząstek stałych z małych skuterów dwu- i czterosuwowych Częśśc 1}

\begin{abstract}
W artykule przedstawiono badanie uregulowanych i nieuregulowanych prawnie emisji czastek dla klasycznego i nowoczesnego skutera 2-suwowego i typowego skutera 4-suwowego zasilanych paliwami o różnym udziale etanolu. Ponadto zamieszczono porównanie dwóch różnych paliw etanolowych: czystego etanolu (E) i wodnego etanolu (EH) zawierającego 3,9\% wody i skażonego 1,5-procentowym stężeniem benzyny. Szczególnie skupiono sie na badaniach wodnego etanolu, od chwili, gdy koszty produkcji etanolu z dodatkiem wody okazaty się mniejszy niż etanolu bez takiego dodatku.

Pojazdy sq wyposażone w gaźnikowy uktad zasilania i nie posiadaja reaktora katalitycznego, co stanowi najczęstsze rozwiąanie konstrukcyjne w Azji Wschodniej, umożliwiajac uzyskanie tym samym informacji o emisji z silnika.

Pomiary emisji spalin przeprowadzono na paliwach zawierajacych etanol (E) lub wodny etanol (EH) o udziale objetościowym odpowiednio 5, 10, 15 i 20\%. Podczas pomiaru dokonywano systematycznej analizy masy czastek statych $i$ liczby nanoczastek (NP).

Obecne prace badawcze nie dotyczyly trwałości elementów poddanych chemicznemu oddziaływaniu etanolu. Ponadto nie uwzględniono tzw. "zimnego startu”, szczególnie w warunkach granicznych oraz rozcieńczenia oleju smarujacego.

Słowa kluczowe: etanol, emisja czastek stałych, silniki 2-suwowe, skutery
\end{abstract}

\section{Introduction}

The growth to sustainability of the transportation fuels is highly stimulated by the EU directives and blending of $5.75 \%$ fuel derived from biomass should be achieved in 2010 and the legislation is aiming for $20 \%$ into the year 2020. Ethanol produced by fermentation of corn (the first generation) and biomass (the second generation) and methyl esters of fats and oils (the first/second generation bio diesel) are the renewable fuel. Several countries have objectives to substitute a part of the energy of traffic by ethanol as the renewable energy source.

Laboratories for IC-Engines and Exhaust Emission Control (AFHB) of the University of Applied Sciences, Biel, Switzerland are involved since 2000 in several research projects about emission factors and possibilities of reduction of (nano)particle emissions of 2-wheelers. A special attention

\section{Wprowadzenie}

Wzrost możliwości dostarczania paliw w transporcie jest w znacznej mierze stymulowany dyrektywami Unii Europejskiej, dzięki którym w 2010 r. zastosowano mieszankę zawierającą 5,75\% paliwa otrzymanego z biomasy; ustawodawca zamierza osiągnąć w 2020 r. mieszankę zawierającą $20 \%$ biomasy. Etanol wytworzony w procesie fermentacji kukurydzy (pierwsza generacja) i biomasy (druga generacja) estrów metylowych tłuszczy i olejów (biodiesel pierwszej/ drugiej generacji) stanowią paliwa odnawialne. Kilka państw pragnie zastąpić część energii w ruchu ulicznym tą, która jest zawarta w etanolu jako odnawialnym źródle energii.

Laboratoria Silników Spalinowych i Kontroli Emisji Spalin (AFHB) Uniwersytetu Nauk Stosowanych w Biel, w Szwajcarii, są zaangażowane od 2000 r. w kilka projektów badawczych dotyczących czynników emisji i możliwości 
was paid to the 2-stroke scooters, which have much higher particle emission, than the 4-strokers.

In an international network project, treating about analytics and possibilities of reduction of (nano)particle emissions from 2-S scooters, several topics were investigated [1 - 6] and the combinations of technical measures to lower the particle emissions of scooters confirmed the expected effects and showed considerable reduction potentials. These technical measures were:

- higher tier lube oils

- lower oil dosing

- active oxidation catalyst

- supplementary filtration \& oxidation device (wire-mesh filter-catalyst WFC)

- special fuel.

The special fuel used in those tests was Alkylat Aspen gasoline with a uniform HC-matrix (mostly isooctane) and no aromatics. This special gasoline is recommended in Switzerland for the hand-held machines in professional application.

The idea of using ethanol blends was known, but not applied before in the research of scooters.

Ethanol is used for passenger cars for a long time (Brazil). In the last years, due to the increasing prices of crude oil, there is a growing interest for ethanol. Several countries have objectives to substitute a part of the energy of traffic by the renewable energy. On the other hand there are interferences with the prices of food in certain regions.

Some manufacturers offer FFV (flex fuel vehicles), which is particularly challenging for high ethanol content (E85) in countries, like Sweden with colder climatic conditions. There are several technical problems to resolve to guarantee the long live operation of the engine with E85 [7 - 11]:

- adaptation of engine construction in regard to a changed thermal stress of combustion chamber parts,

- adaptation of spark plugs and injectors,

- fuel injection system,

- wear of valves, pistons, rings and liners,

- polymer materials and sealings,

- crankcase ventilation and oil dilution,

- software of engine ECU, new or flexible parameter settings.

Small portions of ethanol E5 are generally accepted for the vehicle fleets without any adaptations.

Very useful information about handling of gasolineethanol blends up to $10 \% \mathrm{v} / \mathrm{v}$ is given in the CONCAWE report No. 3/08 [12].

The objectives of the present work are to investigate the limited and the unregulated emissions of typical 2-stroke and 4-stroke scooters $50 \mathrm{cc}$ with different ethanol blend fuels, with pure and hydrous ethanol. The vehicles are with carburettor and without catalyst, which represents the most frequent technology in Eastern Asia and offers the information of engine-out emissions.

Ethanol fuel specifications worldwide traditionally dictate use of anhydrous ethanol (less than 1\% water) for gasoline blending. This result in additional costs, energy zmniejszenia emisji nanocząstek pojazdów dwukołowych. Szczególną uwagę poświęcono skuterom 2-suwowym, u których występuje znacznie większa emisja cząstek stałych niż u skuterów z silnikami 4-suwowymi.

W ramach międzynarodowego projektu sieciowego, dotyczącego obliczeń i możliwości zmniejszenia emisji nanocząstek ze skuterów 2-suwowych, rozważano wybrane problemy naukowe [1 -6], a zastosowane do ich rozwiązania środki techniczne zmierzające do obniżenia emisji cząstek stałych z silników tych pojazdów potwierdziły, przez odpowiednie wyniki działań, że istnieją potencjalne możliwości obniżenia emisji cząstek stałych ze skuterów.

Do zastosowanych środków technicznych zmierzających do obniżenia emisji cząstek stałych z silników spalinowych skuterów należały:

- wyższa klasa oleju smarującego

- mniejsze dawkowanie oleju

- aktywny utleniający reaktor katalityczny

- dodatkowe urządzenie filtracyjno-utleniające (filtr siatkowy, reaktor WFC)

- specjalne paliwo.

Zastosowane $\mathrm{w}$ badaniach specjalne paliwo stanowiła benzyna alkilat-topola (Alkylat Aspen) z jednorodną strukturą HC (głównie izooktan) bez udziału węglowodorów aromatycznych. Ta specjalna benzyna jest zalecana w Szwajcarii dla maszyn ręcznych do specjalistycznych zastosowań.

Idea zastosowania mieszanek etanolowych była znana, lecz nie zastosowana w badaniach skuterów.

Etanol jest stosowany od dawna w samochodach osobowych (Brazylia). W ostatnich latach, z powodu wzrastających cen ropy naftowej, zwiększa się zainteresowanie etanolem.

Niektóre z państw pragną zastąpić część energii zużywanej przez środki transportu w ruchu ulicznym energią, która jest uzyskiwana ze źródeł odnawialnych. Należy jednak pamiętać, iż takie działanie ma wpływ na wzrost cen żywności w danych regionach.

Niektórzy producenci oferują pojazdy wielopaliwowe (FFV - flex fuel vehicles), co stanowi szczególne wyzwanie dla paliw o dużej zawartości etanolu (E85) w krajach o chłodniejszym klimacie, jak np. Szwecja. Istnieje kilka problemów technicznych do rozwiązania celem zapewnienia długiego okresu pracy silnika przy stosowaniu paliwa E85 $[7-11]$ :

- przystosowanie konstrukcji silnika do zmienionych naprężeń termicznych elementów komory spalania,

- rozmieszczenie świec zapłonowych i wtryskiwaczy,

- system wtrysku paliwa,

- zużycie zaworów, tłoków, pierścieni tłokowych i tulei cylindrowych,

- materiały polimerowe,

- przewietrzanie skrzyni korbowej i rozcieńczanie oleju smarującego,

- oprogramowanie sterownika ECU silnika, nowe lub elastyczne ustawienia parametrów.

Niewielkie udziały etanolu są ogólnie akceptowane dla floty pojazdów bez konieczności wprowadzania jakichkolwiek zmian. 
usage and environmental impacts associated with the extra processing step required to dehydrate the hydrous ethanol produced via distillation ( $4-5 \%$ water) to meet the current anhydrous ethanol specifications. For saving costs and energy the hydrous ethanol may be effectively used in most ethanol/gasoline blending applications, reducing or eliminating the need for anhydrous ethanol production and distribution $[13,14]$. The hydrous ethanol is predisposed to be a subject to standardisation and acceptance by major stakeholders in the fuel and automotive industries.

During the tests a systematical analysis of particle mass (PM) and nanoparticles counts (NP) was performed.

\section{Investigated scooters}

The research of emissions with alcohol was performed on the Piaggio Typhoon 2-stroke and with an older type 2-stroke Kreidler Florett small motorcycle (lube oil directly mixed with the fuel). Figure 1 shows both vehicles in the laboratory and Table 1 represents the most important data.

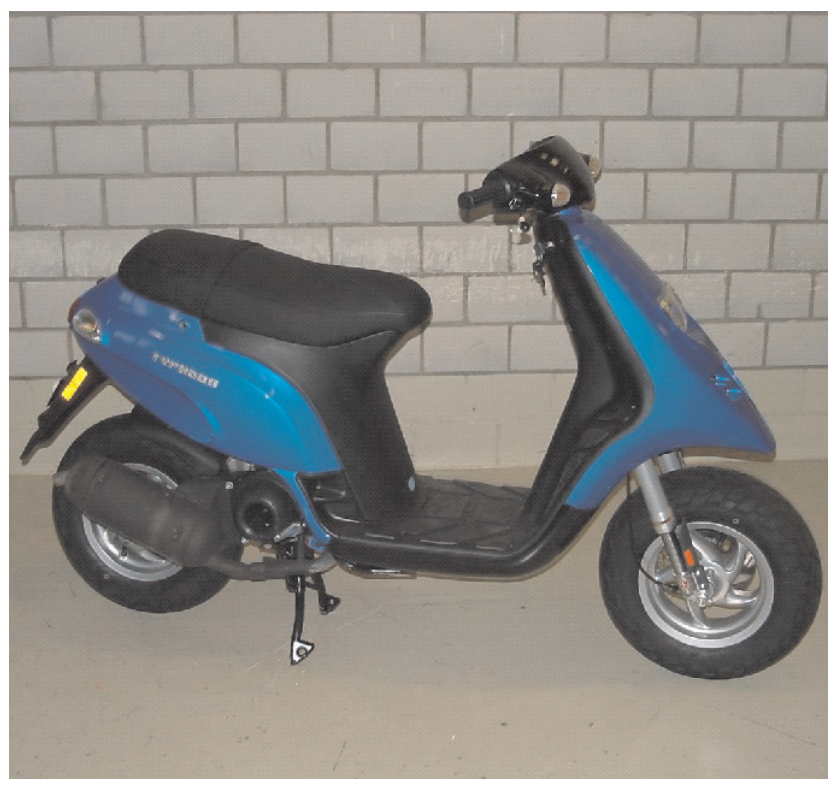

Bardzo pomocne informacje dotyczące mieszanek benzyny i etanolu aż do udziału objętościowego równego 10\% można uzyskać w raporcie CONCAWE nr 3/08 [12].

Celem niniejszej pracy jest zbadanie limitowanych oraz nieuregulowanych przepisami emisji typowych skuterów dwui czterosuwowych o objętości skokowej silnika równej $50 \mathrm{~cm}^{3}$ dla paliw o różnym udziale etanolu, czystego etanolu i etanolu z dodatkiem wody. Pojazdy są wyposażone w gaźnikowy układ zasilania i nie posiadają reaktora katalitycznego - jest to najczęściej spotykane rozwiązanie konstrukcyjne skuterów użytkowanych w Azji Wschodniej, a uzyskana emisja składników szkodliwych spalin z tych pojazdów daje informacje o rzeczywistej emisji w układzie wylotowym silnika.

Parametry techniczne paliwa etanolowego, w skali światowej, tradycyjnie wymuszają użycie bezwodnego etanolu (mniej niż 1\% wody) dla mieszanek benzynowych. Prowadzi to do dodatkowych kosztów związanych z jego wytworzeniem, do zwiększenia zużycia energii i wiąże się z wpływem na środowisko naturalne dodatkowego procesu jego przetwarzania wymaganego w celu odwodnienia wodnego etanolu wytworzonego w procesie destylacji ( $4-5 \%$ wody), aby spełnić obecne wymagania techniczne bezwodnego etanolu. W celu zmniejszenia kosztów i zużycia energii, wodny etanol może być efektywnie użyty w większości zastosowań mieszanek etanolu i benzyny, zmniejszając lub eliminując

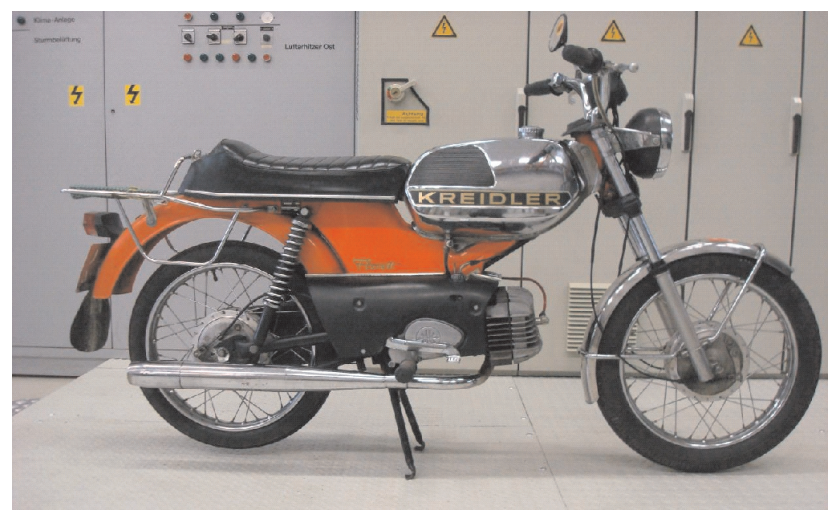

Fig. 1. Investigated 2-S Scooter: a) Piaggio Typhoon 2-S 50 cc, b) Kreilder Florett 2-S 50cc

Rys. 1. Badane 2-suwowe skutery: a) Piaggio Typhoon o objętości skokowej $50 \mathrm{~cm}^{3}$, b) Kreilder Florett o objętości skokowej silnika $50 \mathrm{~cm}^{3}$

The investigated 4-S Scooter was Honda Zoomer with carburettor and without catalyst, Fig. 2. The most important data of this vehicle represents Table 2.

All vehicles use simple conventional carburettors with a cable-controlled throttle body and needle.

\section{Fuels}

As a basic fuel a standard gasoline, lead-free, RON 95, Swiss market quality was used. At the beginning of network projects about the particle emissions of 2-S scooters 2004 a large batch of this gasoline was purchased to perform all research with the same fuel.

The sulphur content of this gasoline was analysed and no sulphur was found (detection limit $<2 \mathrm{ppm}$ ). The investigated fuel blends contained ethanol (E), or hydrous ethanol (EH) in potrzebę produkcji i dystrybucji bezwodnego etanolu [13, 14]. Wodny etanol jest paliwem akceptowanym przez główne podmioty przemysłu paliwowego i samochodowego.

Podczas badań dokonywano systematycznej analizy masy cząstek (PM) i liczby nanocząstek (NP).

\section{Badane skutery}

Badania emisji pojazdu zasilanego alkoholem przeprowadzono na 2-suwowym skuterze Piaggio Typhoon i starszym małym 2-suwowym skuterze Kreidler Florett (rozwiązanie konstrukcyjne, w którym olej smarujący jest wymieszany bezpośrednio z paliwem).

Na rysunku la i 1 b przedstawiono oba pojazdy w laboratorium, a w tabeli 1 zawarto najważniejsze ich dane techniczne. 
Table 1. Data of the investigated 2-S scooters

Tabela 1. Dane techniczne badanych skuterów

\begin{tabular}{|c|c|c|}
\hline- & Piaggio & Kreidler \\
\hline $\begin{array}{l}\text { Vehicle identification/oznaczenie } \\
\text { pojazdu }\end{array}$ & typhoon & K54/511 Florett RS \\
\hline Model year/model roku & 2004 & 1976 \\
\hline $\begin{array}{l}\text { Transmission no. of gears/rodzaj } \\
\text { przektadni i liczba biegów }\end{array}$ & variomat & $\mathrm{m} 5$ \\
\hline $\mathrm{Km}$ at beginning/stan licznika $[\mathrm{km}]$ & 670 & 8316 \\
\hline $\begin{array}{l}\text { Engine/silnik } \\
\text { Type/typ } \\
\text { Displacement/objętość skokowa }\left[\mathrm{cm}^{3}\right]\end{array}$ & $\begin{array}{l}2 \text { stroke } \\
50\end{array}$ & $\begin{array}{l}2 \text { stroke } \\
50\end{array}$ \\
\hline Number of cylinders/liczba cylindrów & 1 & 1 \\
\hline Cooling/rodzaj chtodzenia & air cooled/powietrzem & air cooled/powietrzem \\
\hline $\begin{array}{l}\text { Rated power/znamionowa moc uży- } \\
\text { teczna }[\mathrm{kW}]\end{array}$ & 3.2 & 3.93 \\
\hline $\begin{array}{l}\text { Rated speed rpm/prędkość znamiono- } \\
w a \text { [obr/min] }\end{array}$ & 6500 & 7000 \\
\hline $\begin{array}{l}\text { Idling speed } \mathrm{rpm} / \text { prędkość biegu } \\
\text { jałowego }[\mathrm{obr} / \mathrm{min}]\end{array}$ & 1800 & 1800 \\
\hline $\begin{array}{l}\text { Max vehicle speed/maks. prędkość } \\
\text { pojazdu }[\mathrm{km} / \mathrm{h}]\end{array}$ & 45 & 70 \\
\hline Weight empty/masa własna $[\mathrm{kg}]$ & 84 & 93 \\
\hline $\begin{array}{l}\text { Mixture preparation/przygotowanie } \\
\text { mieszanki }\end{array}$ & $\begin{array}{l}\text { carburettor with automatic } \\
\text { oil pump/gaźnik z automa- } \\
\text { tyczna pompa olejowa }\end{array}$ & $\begin{array}{l}\text { carburettor blend } 2 \% \text { lube oil } \\
\text { in gasoline/gaźnik; dodatek } \\
2 \% \text { oleju smarujacego } \\
\text { w benzynie }\end{array}$ \\
\hline $\begin{array}{l}\text { SAS (secondary air system) } / \text { system } \\
\text { powietrza wtórnego }\end{array}$ & Yes/tak & No/nie \\
\hline Catalyst/reaktor katalityczny & Dummy/atrapa & No/nie \\
\hline
\end{tabular}

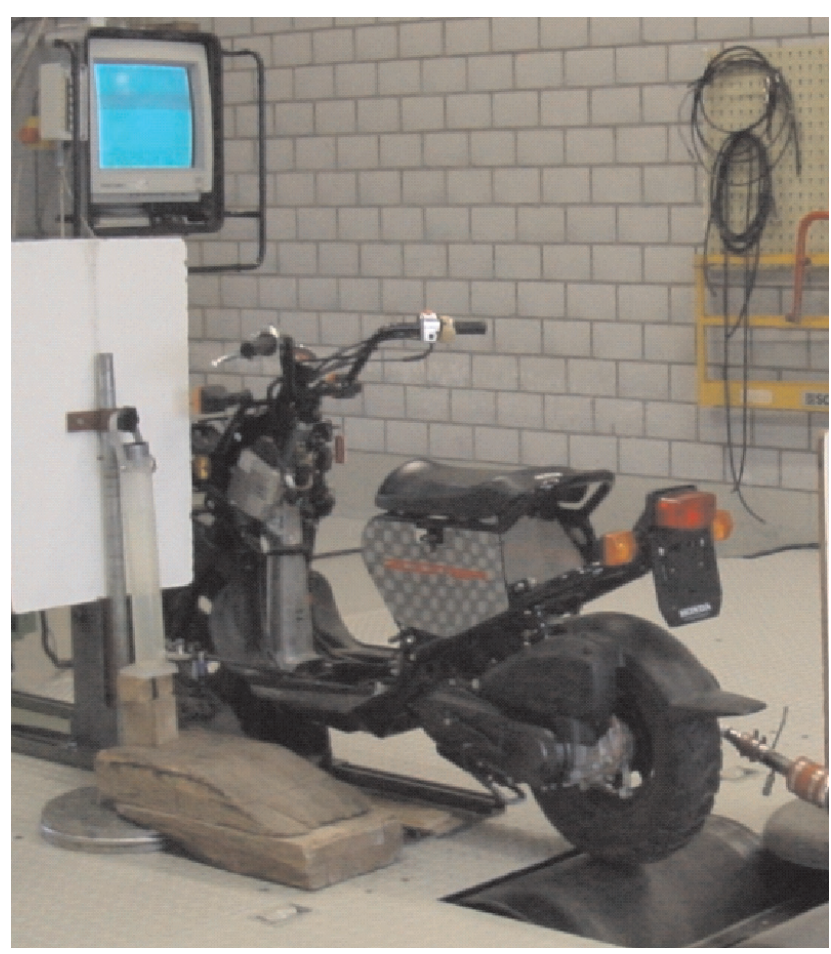

Fig. 2. Investigated 4-S scooter: Honda Zoomer 4-S $50 \mathrm{cc}$ Rys. 2. Badany 4-suwowy skuter Honda Zoomer o objętości skokowej
Wszystkie pojazdy posiadają konwencjonalne gaźniki ze sterowaną linką przepustnicą i iglicą.

\section{Paliwa}

Jako paliwo podstawowe zastosowano standardową benzynę bezołowiową, RON 95, zgodną z jakością stosowanych paliw w Szwajcarii.

$\mathrm{Na}$ początku projektu sieciowego dotyczącego emisji cząstek stałych ze skuterów 2-suwowych 2004 zakupiono znaczną ilość benzyny w celu przeprowadzenia badań na tym samym paliwie. Dokonano analizy zawartości siarki $w$ powyższej benzynie, w wyniku której stwierdzono brak powyższego składnika (granica wykrycia $<2$ ppm). Badana mieszanka paliwowa zawierała etanol (E) lub wodny etanol (EH) o udziale objętościowym 5, 10, 15 i 20\%.

Czysty etanol stanowi $\mathrm{C}_{2} \mathrm{H}_{5} \mathrm{OH}$, a etanol wodny zawiera: etanol $94,56 \%$ objętości, wode $-3,94 \%$ objętości i benzynę - $1,5 \%$ objętości.

$\mathrm{W}$ tabeli 3 zamieszczono najważniejsze dane o paliwach zastosowanych w badaniach. Można zauważyć, iż wraz ze wzrostem udziału etanolu wymaganie dotyczące ilości powietrza niezbędnego do spalania stechiometrycznego zmniejsza się. Oznacza to (ze względu na w przybliżeniu stały strumień powietrza), że mieszanka paliwowo-powietrzna będzie uboższa. Ponadto występuje mniejsza wartość ciepła w etanolu. Punkt wrzenia dla stałej temperatury i duże utajone ciepło parowania etanolu mogą powodować duże trudności podczas uruchamiania silnika w niskich temperaturach.

\section{Oleje smarujące}

Zastosowane oleje smarujące były zgodne z wymaganiami producentów pojazdów:

- dla skutera Piaggio Typhoon - olej syntetyczny Selenia HI-Scooter 2 TECH, kod produktu: 1050, Piaggio 2966, API TC ++

- dla skutera Kleider Florett - olej syntetyczny Motorex Nbr. 4 [15]

- dla skutera Honda Zoomer - Motorex 10W-40, API SG.

\section{Aparatura pomiarowa}

\section{Hamownia podwoziowa}

- hamulec rolkowy: Schenk 500 G5 60

- system sterowania kierowcy: Zöllner FLG, 2Typ. RP 0927-3d, Progr., wersja 1.4

- system CVS: Horiba CVS 9500T z dmuchawą Rootsa

- klimatyzacja w hali pomiarowej (powietrze wlotowe i rozcieńczające - automatyczna, temperatura: $20-30{ }^{\circ} \mathrm{C}$, wilgotność: $5,5-12,2 \mathrm{~g} / \mathrm{kg}$ 
the portions of 5, 10, 15 and $20 \%$ by volume. Pure ethanol is $\mathrm{C}_{2} \mathrm{H}_{5} \mathrm{OH}$ and the hydrous ethanol contains: $94.56 \%$ vol ethanol, $3.94 \%$ vol water and $1.5 \%$ gasoline. The most important parameters of the fuels used are summarized in the Table 3.

It can be seen, that with increasing the ethanol ratio the stoichiometric air requirement of the blendfuel decreases. That means by an approximately equal air flow rate the airfuel-mixture will be leaner. Furthermore there is less heat value in ethanol. The boiling point at a fix temperature and the high latent heat of evaporation of ethanol may cause serious problems of cold starting.

\section{Lube oils}

The lube oils used were according to the requirements of vehicle manufacturers:

- for Piaggio Typhoon - fully synthetic Selenia HI-Scooter 2

TECH oil, product code: 1050, Piaggio 2966, API TC ++

- for Kleider Florett - fully synthetic oil Motorex Nbr. 4, [15]

- for Honda Zoomer - Motorex 10W-40, API SG.

\section{Measuring apparatus \& procedures}

Chassis dynamometr

- roller dynamometer: Schenk 500 G5 60

- driver conductor system: Zöllner FLG, 2Typ. RP 0927-3d, Progr., Version 1.4

- CVS dilution system: Horiba CVS 9500T with Roots blower

- air conditioning in the measuring hall (intake and dilution air) automatic, temperature: $20-30{ }^{\circ} \mathrm{C}$, humidity: $5.5-12.2 . \mathrm{g} / \mathrm{kg}$

The measuring set-up on a chassis dynamometer is represented in Fig. 3.

\section{Test equipment for regulated exshaust gas emissions}

This equipment fulfills the requirements of the Swiss and European exhaust gas legislation - 70/220/EEC - 2003/76/ EC; 97/24/EC - chap. 5-2002/51/EC.

- Gaseous components:

exhaust gas measuring system Horiba MEXA-9400H

$\mathrm{CO}, \mathrm{CO}_{2}$ infrared analyzers (IR)

$\mathrm{HC}_{\mathrm{IR}} \quad$ only for idling

$\mathrm{HC}_{\mathrm{FID}} \quad$ flame ionization detector for total hydrocarbons

$\mathrm{NO} / \mathrm{NO}_{\mathrm{x}} \quad$ chemoluminescence analyzer (CLA)

$\mathrm{O}_{2} \quad$ Magnos (paramagnetic analyzer)
Table 2. Date of the investigated 4-S scooter

Tabela 2. Dane techniczne badanego skutera 4-suwowego

\begin{tabular}{|l|c|}
\hline- & Honda \\
\hline Vehicle identification/oznaczenie pojazdu & Zoomer NPS 50 \\
\hline Model year/model roku & 2004 \\
\hline $\begin{array}{l}\text { Transmission no. of gears/rodzaj przekładni } \\
\text { i liczba biegów }\end{array}$ & variomat \\
\hline Km at beginning/stan licznika & $74 \mathrm{~km}$ \\
\hline $\begin{array}{l}\text { Engine/silnik: } \\
\text { Type/rodzaj } \\
\left.\text { Displacement/objętość skokowa } \text { [cm }{ }^{3}\right] \\
\text { Number of cylinders/liczba cylindrów }\end{array}$ & 4 stroke/4-suwowy \\
\hline Cooling/rodzaj chłodzenia & 50 \\
\hline $\begin{array}{l}\text { Rrated power/znamionowa moc } \\
\text { użyteczna }[\mathrm{kW}]\end{array}$ & water cooled/wodne \\
\hline $\begin{array}{l}\text { Rated speed, rpm/prędkość znamionowa } \\
\text { [obr/min] }\end{array}$ & 3.1 \\
\hline $\begin{array}{l}\text { Idling speed, rpm/prędkość biegu jałowego } \\
\text { [obr/min] }\end{array}$ & $1600-1800$ \\
\hline $\begin{array}{l}\text { Max vehicle speed/maks. prędkość pojazdu } \\
\text { [km/h] }\end{array}$ & dummy/atrapa \\
\hline Weight empty/masa własna [kg] & yes/tak \\
\hline $\begin{array}{l}\text { Mixture preparation/przygotowanie mie- } \\
\text { szanki }\end{array}$ & carburettor/gaźnik \\
\hline $\begin{array}{l}\text { SAS (secondary air system)/system powie- } \\
\text { trza wtórnego }\end{array}$ & \\
\hline Catalyst/reaktor katalityczny & \\
\hline
\end{tabular}

Na rysunku 3 przedstawiono stanowisko pomiarowe na hamowni podwoziowej.

\section{Wyposażenie badawcze dla normatywnych badań emisji spalin}

Wyposażenie badawcze dla normatywnych badań emisji spełnia wymagania szwajcarskich i europejskich unormowań prawnych w zakresie emisji spalin: 70/220/EEC - 2003/76/ EC; 97/24/EC - rozdz. 5 - 2002/51/EC.

- Składniki gazowe:

system do pomiaru emisji spalin Horiba MEXA-9400H

$\mathrm{CO}, \mathrm{CO}_{2}$ analizator na podczerwień (IR - infrared analyzers)

$\mathrm{HC}_{\mathrm{IR}} \quad$ jedynie dla biegu jałowego

$\mathrm{HC}_{\mathrm{FID}}$ analizator płomieniowo-jonizacyjny dla całkowitej ilości węglowodorów

Table 3. Parameters of fuels used [9]

Tabela 3. Parametry zastosowanych paliw [9]

\begin{tabular}{|c|c|c|c|c|c|c|c|c|c|}
\hline & & $\begin{array}{l}\text { Gasoline/ } \\
\text { benzyna }\end{array}$ & $\begin{array}{c}\text { Ethanol/ } \\
\text { etanol } \\
\mathrm{C}_{2} \mathrm{H}_{5} \mathrm{OH}\end{array}$ & E10 & E15 & E20 & EH10 & EH15 & $\mathrm{EH} 20$ \\
\hline Density/gęstość & {$\left[\mathrm{g} / \mathrm{cm}^{3}\right]$} & 0.737 & 0.789 & 0.742 & 0.745 & 0.747 & 0.743 & 0.746 & 0.749 \\
\hline $\begin{array}{l}\text { Stoichiometric air/fuel ratio/stechiometr. wsp. powietrze/ } \\
\text { paliwo }\end{array}$ & {$[-]$} & 14.6 & 9.0 & 14.00 & 13.71 & 13.42 & 13.96 & 13.64 & 13.33 \\
\hline Lover caloric value/dolna wartość opałowa & {$[\mathrm{MJ} / \mathrm{kg}]$} & 43.0 & 26.8 & 41.3 & 40.4 & 39.6 & 41.1 & 40.2 & 39.3 \\
\hline *) boiling point/temp. wrzenia & {$\left[{ }^{\circ} \mathrm{C}\right]$} & $30-200$ & 78.5 & & & & & & \\
\hline$\left.{ }^{*}\right)$ research octane nbr./badawcza liczba oktanowa & {$[-]$} & 95 & 111 & & & & & & \\
\hline *) latent heat of evaporation/utajone ciepło parowania & {$[\mathrm{kJ} / \mathrm{kg}]$} & 420 & 845 & & & & & & \\
\hline
\end{tabular}

*) according to [9]/zgodnie z [9] 
The dilution ratio DF in the CVS-dilution tunnel is variable and can be controlled by means of the $\mathrm{CO}_{2}$ analysis.

- Measurement of the particulate mass (PM): sampling from the full-flow dilution tunnel filter temperature $-52{ }^{\circ} \mathrm{C}$ conditioning of filter: $8-24 \mathrm{~h}\left(20^{\circ} \mathrm{C}\right.$, rel. humidity $\left.50 \%\right)$ scale: Mettler, accuracy $\pm 1 \mu \mathrm{g}$

\section{Particle size analysis}

In addition to the gravimetric measurement of particulate mass, the particle size and counts distributions were analyzed with following apparatus:

- SMPS - Scanning Mobility Particle

Sizer, TSI (DMA TSI 3081L, CPC TSI 3772)

- NanoMet - System consisting of:

- PAS - Photoelectric Aerosol Sensor (Eco Chem PAS 2000)

- DC - Diffusion Charging Sensor (Matter Eng. LQ1$\mathrm{DC})$

- MD19 tunable minidiluter (Matter Eng. MD19-2E, see Fig. 3).

SMPS enables to count nanoparticles according to their size distribution $(10-400 \mathrm{~nm})$. PAS (photoelectric aerosol sensor) is sensitive to the surface of particulates and to the chemical properties of the surface. It indicates the solid particles with carbonaceous surface. This type of particles
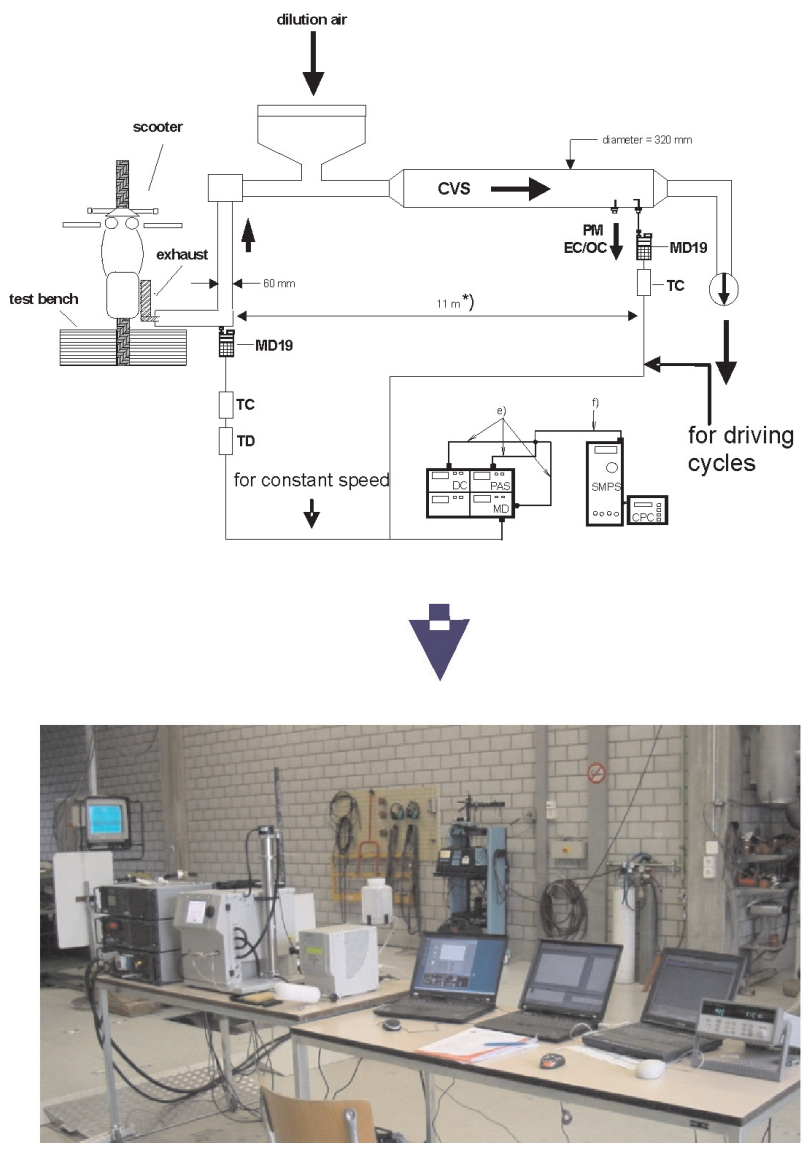

Fig. 3. Sampling and measuring set-up for nanoparticulate analysis of scooters

Rys. 3. Stanowisko poboru spalin i pomiarowe do analizy nanocząstek w spalinach silników skuterów
$\mathrm{NO} / \mathrm{NO}_{x}$ analizator chemiluminescencyjny (CLA)

$\mathrm{O}_{2} \quad$ analizator paramagnetyczny

Współczynnik rozcieńczenia w tunelu rozcieńczającym

CVS jest zmienny i może być regulowany za pomocą

środków technicznych stosujących ocenę $\mathrm{CO}_{2}$.

- Pomiar masy cząstki stałej (PM): próbkowanie z pełnoprzepływowego tunelu rozcieńczającego, temperatura filtra $-52{ }^{\circ} \mathrm{C}$, kondycjonowanie filtra: $8-24 \mathrm{~h}\left(20^{\circ} \mathrm{C}\right.$, wilgotność względna 50\%), skala: Mettler, dokładność $\pm 1 \mu \mathrm{g}$.

\section{Analiza rozmiaru cząstki}

Oprócz grawimetrycznego pomiaru masy cząstki, analizowano rozkład wymiarowy i liczbę cząstek z zastosowaniem następującej aparatury:

- SMPS - skaningowy analizator wymiarowy cząstek stałych oparty na analizie ruchliwości elektrycznej cząstek Sizer, TSI (DMA TSI 3081L, CPC TSI 3772)

- NanoMet - system zawierający:

- PAS - fotoelektryczny czujnik aerozolu (Eco Chem PAS 2000)

- DC - czujnik rozcieńczenia ładunku (Matter Eng. LQ1$\mathrm{DC})$

- MD19 minitunel rozcieńczający (Matter Eng. MD192E, patrz rys. 3 ).

SMPS umożliwia pomiar nanocząstek zgodnie z ich rozkładem wymiarowym $(10-400 \mathrm{~nm})$.

Czujnik PAS jest wrażliwy na powierzchnię cząstek i chemiczne właściwości powierzchni. Wskazuje stałe cząstki z powierzchnią węglową. Ten rodzaj cząstek jest rzadko możliwy do pomiaru w spalinach silników 2-suwowych, stąd wyniki PAS nie są przedstawione w powyższej pracy.

Przetwornik DC umożliwia pomiar całkowitej powierzchni cząstki niezależnie od chemicznych właściwości. Wskazuje cząstki stałe i kondensaty. Wyniki uzyskane z zastosowaniem przetwornika DC są bardzo zgodne ze zmierzoną masą cząstki stałej. Na rysunku 3 przedstawiono stanowisko poboru spalin i pomiarowe zastosowane $\mathrm{w}$ badaniach.

Próbkowanie pomiarów nanocząstek jest dokonywane w przewodzie wylotowym silnika dla podstawowych badań przy stałej prędkości, a dla cykli jezdnych pobór próbki jest z systemu CVS (zgodnie z PMP). Minitunel MD19 jest grzany do temperatury $120{ }^{\circ} \mathrm{C}$. Wszystkie pomiary zrealizowane $\mathrm{w}$ pracy przeprowadzono bez zastosowania termoklimatyzatora (TC).

Praca gorącego silnika w warunkach stacjonarnych została przedłużona do 20 minut w celu uzyskania wystarczającej masy cząstek na filtrze pomiarowym do analizy PM. Wartości graniczne dla stanowiska pomiarowego ustalono zgodnie ze szwajcarskimi unormowaniami prawnymi w zakresie emisji spalin dla motocykli (masa odniesienia $170 \mathrm{~kg}$; $\mathrm{a} / \mathrm{b} / \mathrm{c}=10 / 0 / 0,0245$, pochłonięta moc $0.547 \mathrm{~kW} / 40 \mathrm{~km} / \mathrm{h}$ ).

\section{Procedury badawcze}

Badania podstawowe z zastosowaniem paliw opartych na etanolu przeprowadzono dla każdego wariantu paliwa 
is rarely measurable in the 2-S exhaust gas and the results of PAS are not represented in this paper.

DC (diffusion charging sensor) measures the total particle surface independent of the chemical properties. It indicates the solids and the condensates. The results of DC correspond very well with the measured particle mass PM. The sampling and measuring set-up during the tests is shown in Fig. 3.

The sampling position for NP-measurements is at tailpipe (TP) for basic investigations at constant speed and for driving cycles the sampling position from CVS (according to PMP) is used. The minidiluter MD19 is heated to $120^{\circ} \mathrm{C}$. All NP-measurements in this work were performed without the thermoconditioner (TC). The stationary warm operation was prolonged until 20 min to get enough mass on the measuring filters for the analysis of PM. The driving resistances of the test bench were set according to the Swiss exhaust gas legislation for motorcycles. (reference mass $170 \mathrm{~kg}$; a/b/c = =10/0/0.0245; absorbed power0.547 kW@40 km/h).

\section{Research procedures}

The basic investigations with ethanol-based fuels were performed with each variant of fuel according to the same procedure:

-5 min conditioning at full load

- legal test cycle

- for Piaggio Typhoon limited to $45 \mathrm{~km} / \mathrm{h}$ ECE $47^{1)}$

- for Kreidler and Honda unlimited speed ECE 402)

- constant speed $40 \mathrm{~km} / \mathrm{h}$

- first 5 min conditioning

- further $10 \mathrm{~min}$ measurements of PSD's with SMPS

- last 3 min - last scan SMPS.

The legal driving cycles are represented in Fig. 4.

\section{Acknowledgements}

The authors would like to express their gratitude for the support of the project to BAFU (Swiss EPA), Dr. M. Schiess and to the Process Design Center B.V.NL and TU Delft.

Paper reviewed/Artykut recenzowany

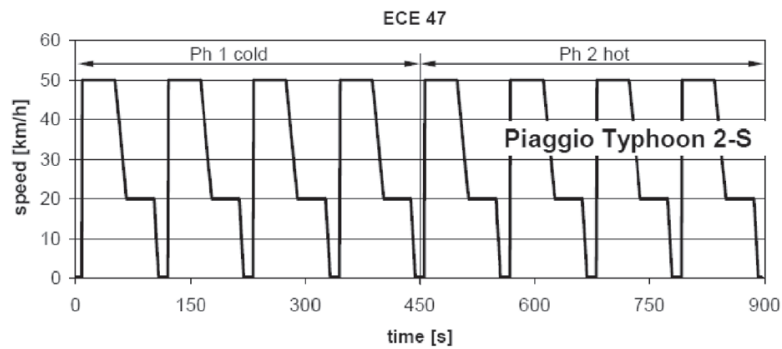

ECE 40

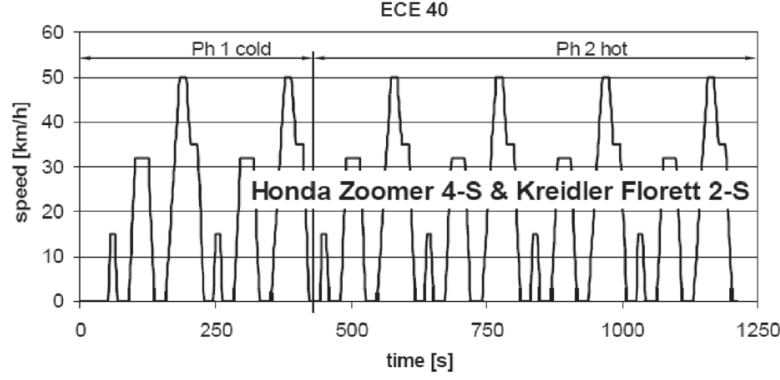

Fig. 4. Legal driving cycles used for the investigated vehicles

Rys. 4. Cykle jezdne zastosowane dla badanych pojazdów

zgodnie z tą samą procedurą:

- 5 min kondycjonowania dla pełnego obciążenia

- normatywny cykl badawczy

- dla skutera Piaggio Typhoon ograniczony do $45 \mathrm{~km} / \mathrm{h}$ ECE 47 ${ }^{1)}$

- dla skutera Kreidler i Honda prędkość bez ograniczenia ECE $40^{2)}$

- stała prędkość $40 \mathrm{~km} / \mathrm{h}$

- pierwsze 5 min kondycjonowanie

- następne 10 min pomiary PSD's z zastosowaniem SMPS

- ostatnie $3 \mathrm{~min}$ - ostatnie skanowanie SMPS.

Normatywne cykle jezdne przedstawiono na rys. 4 .

\section{Podziękowania}

Autorzy pragną wyrazić podziękowania za pomoc w realizacji projektu następującym osobom i instytucjom: Federalnemu Urzędowi ds. Środowiska (Szwajcarski oddział EPA) i dr. M. Schiess, Process Design Center B.V.NL oraz TU Delft.

\section{Nomenclature/Skróty i oznaczenia}

AFHB Abgasprüfstelle der Fachhochschule, Biel CH(Lab. For Exhaust Gas Control, Univ. of Appl. Sciences, Biel-Bienne, $\mathrm{CH}) /$ Laboratorium Kontroli Emisji Spalin Uniwersytetu Nauk Stosowanych w Biel-Bienn

BAFU Bundesamt für Umwelt (Swiss EPA)/Federalny Urząd ds. Środowiska (Szwajcarski oddział EPA)

C Carburetor/gaźnik

Carb Carburetor/gaźnik

CMD count median diameter/obliczona średnia wartość średnicy

\footnotetext{
1) according to $97 / 24 / \mathrm{EC}$ chap. 5 annex 1

2) according to $97 / 24 / \mathrm{EC}$ chap. 5 annex 2
}

CPC condensation particle counter/kondensacyjny licznik czastek statych

CVS constant volume sampling/stała objętość próbkowanych spalin

DC diffusion charging sensor/czujnik rozcieńczenia ładunku

DF dilution factor/współczynnik rozcieńczenia

DMA differential mobility analyser/różnicowy analizator rozmiaru cząstek oparty na ocenie ich zmienności ruchowej

E pure ethanol (energy only)/czysty etanol (jedynie energia)

\footnotetext{
1) zgodnie z 97/24/EC rozdz. 5 aneks 1

${ }^{2)}$ zgodnie z 97/24/EC rozdz. 5 aneks 2
} 
EC elemental carbon/węgiel pierwiastkowy

$\mathrm{EH}$ hydrous ethanol/etanol uwodniony

FHB Fachhochschule Biel/Uniwersytet Nauk Stosowanych w Biel

Gas gasoline leed-free, RON 95 (base fuel)/benzyna 95

MD minidiluter/minitunel rozcieńczajacy

ME Matter Engineering, CH/Inżynieria Materiałowa, Szwajcaria

NanoMet minidiluter $+\mathrm{PAS}+\mathrm{DC}(+\mathrm{TC}) /$ minitunel rozcieńczający + fotoelektryczny czujnik aerozolu + czujnik rozcieńczenia tadunku (+ termoklimatyzator)

$\mathrm{NP}$ nanoparticulates $(<1 \mu \mathrm{m}) /$ nanoczastki $(<1 \mu \mathrm{m})$

OC organic carbon/węgiel organiczny

PAS photoelectric aerosol sensor/fotoelektryczny czujnik aerozolu

PM particulate matter, particulate mass/czastka stała

PMP particle measuring program (of the ECE GRPE/program pomiaru czastki (wg ECE GRPE)

\section{Bibliography/Literatura}

[1] Czerwinski J., Comte P., Napoli S., Wili Ph.: Summer Cold Start and Nanoparticulates of Small Scooters. Report B086 for BUWAL (SAEFL) Bern, Lab. For Exhaust Gas Control, Univ. of Appl. Sciences, Biel-Bienne, Switzerland, Nov. 2000. SAE Technical Paper 2002-01-1096.

[2] Czerwinski J., Comte P.: Limited Emissions and Nanoparticles of a Scooter with 2-stroke Direct Injection (TSDI). SAE Technical Paper 2003-01-2314.

[3] Czerwinski J., Comte P., Reutimann F.: Nanoparticle Emissions of a DI 2-Stroke Scooter with varying Oil- and Fuel Quality. SAE Techn. Paper 2005-01-1101.

[4] Czerwinski J., Comte P., Larsen B., Martini G., Mayer A.: Research on Particle Emissions of modern 2-S Scooters. SAE Techn. Paper 2006-01-1078.

[5] Czerwinski J., Comte P., Astorga C., Rey M., Mayer A., Reutimann F.: (Nano) Particle from 2-S Scooters: SOF/INSOF; Improvements of Aftertreatment; Toxicity. AFHB, JRC, TTM, BAFU, SAE Techn. Paper 2007-01-1089.

[6] Czerwinski J., Comte P., Violetti N., Landri P., Mayer A., Reutimann F.: Catalyst Aging and Effects on Particle Emissions of 2-Stroke Scooters. SAE Techn. Paper 2008-01-0455.

[7] Bergström K., Melin S-A., Coleman J.: General Motors Powertrain: The New ECOTEC Turbo BioPower Engine from GM Powertrain - Utilizing the Power of Nature's resources. 28. Internationales Wiener Motorensymposium 2007, Bd.2, S.47.

[8] Bergström K., Nordin H., Königstein A., GM Powertrain Europe; D. Marriott C.D., Wiles M. A., GM Powertrain

Prof. Jan Czerwiński, DEng. - Laboratorium for IC-Engines and Exhaust Gas Control, University of Applied Sciences Biel-Bienne, Switzerland.

Prof. dr Jan Czerwiński - Laboratorium Silników Spalinowych i Emisji Spalin, Uniwersytet Nauk Stosowanych w Biel-Bienne, Szwajcaria. e-mail: jan.czerwinski@bfh.ch

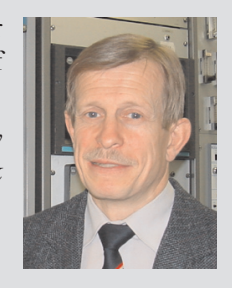

Mr. Pierre Comte - AFHB, University of Applied Sciences, Biel-Bienne, Switzerland.

Pierre Comte - Uniwersytet Nauk Stosowanych, Biel-Bienne, Szwajcaria.

e-mail:pierre.comte@bfh.ch
PSD particles size distribution/rozkład wymiarowy cząstek

$\mathrm{r} \quad$ rich basic tuning/tuning podstawowy $w$ kierunku wzbogacenia mieszanki

SAS secondary air system/system powietrza wtórnego

SMPS scanning mobility particles sizer/skaningowy analizator wymiarowy cząstek statych oparty na analizie ruchliwości elektrycznej czastek

SOF soluble organic fraction/frakcja rozpuszczalna czastki statej

TC thermoconditioner, total carbon/system utrzymania stałej temperatury, calkowita ilość węgla

TP tailpipe/przewód wylotowy silnika

TPN total particle number $[\# / \mathrm{km}] /$ calkowita liczba cząstek [szt./km]

2-S 2 stroke engine/silnik dwusuwowy

4-S 4 stroke engine/silnik czterosuwowy

North America: ABC - Alcohol Based Combustion Engines - Challenges and Opportunities. 16. Aachener Kolloquium Fahrzeug- und Motorentechnik 2007, Bd.2, S. 1031.

[9] Kawai T., Tsunooka T., Chiba F., Uda H., Sonoda Y., Toyota Motor Corporation, Japan: Effect of high Concentration Ethanol on SI Engine Cold Startability and Emissions. 16. Aachener Kolloquium Fahrzeug- und Motorentechnik 2007, Bd.2, S. 1075.

[10] DuMont R.J., Cunningham L.J., Oliver M.K., Studzinski W.M., Galante-Fox J.M.: Controlling Induction System Deposits in Flexible Fuel Vehicles Operating on E85. SAE Techn. Paper 2007-01-4071.

[11] Galante-Fox J.M., Von Bacho P., Notaro C., Zizelman J.: E-85 Fuel Corrosivity: Effects on Port Fuel Injector Durability Performance. SAE Techn. Paper 2007-01-4072.

[12] CONCAWE ... Conservation of Clean Air und Water in Europe, Brussel, http://www.concawe.org.

[13] Gottschalk A.: Gasoline Blending with Hydrous Ethanol. 7th International Colloquium "Fuels", Technische Akademie Esslingen TAE, Jan. 14-15, 2009.

[14] Hydrous Ethanol Blends. HE Blends B.V. www.heblends.com

[15] Czerwinski J., Comte P., Mayer A., Reutimann F., Zürcher D.: Reduction Potentials of Particle Emissions of 2-S Scooters with Combinations of Technical Measures. FISITA, Munich, Germany, Sept. 14-19.2008, Paper F2008-09-014, Congress Proceedings Vol. IV, p. 100, ATZ/ATZ auto technology, Springer Automotive Media, Wiesbaden, D.

Mr. Andreas Mayer, MEng. - Technik Thermische Maschinen (TTM), Switzerland.

Inż. Andreas Mayer - pracownik Termodynamicznej Techniki Maszyn (TTM), Szwajcaria.

e-mail:ttm.a.mayer@bluewin.ch

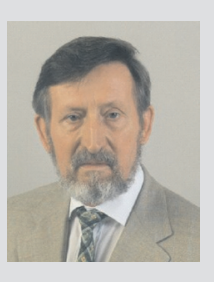

Felix Reutimann - BAFU, Federal Office of Environment, Switzerland.

Felix Reutimann - BAFU, Federalne Biuro Ochrony Środowiska, Szwajcaria.

e-mail:felix.reutimann@bafu.admin.ch 